\title{
IDENTIFIKASI FAKTOR-FAKTOR MANAJEMEN PEMELIHARAAN DAN IMPLEMENTASINYA PADA RUMAH SUSUN DI DKI JAKARTA
}

\author{
The Identification of Maintenance Management Factors and Their \\ Implementation on Flats in Special Capital Region of Jakarta
}

\author{
Eko Priyo Prastyo ${ }^{1}$ dan Andreas F. V. Roy ${ }^{1}$
}

Diterima: 2 Oktober 2017 Disetujui: 10 Januari 2019

\begin{abstract}
Abstrak: Rumah susun (rusun) merupakan bentuk nyata kebijakan pemerintah dalam penyediaan tempat tinggal di daerah perkotaan. Dalam penyelenggaraannya rusun wajib dikelola, dipelihara dan dirawat. Hal tersebut harus dilakukan guna tercapainya cita-cita yang dirumuskan dalam Undang-undang Dasar (UUD) 1945 serta Undang-undang (UU) No.4 tahun 1992 bahwa setiap orang/warga negara berhak hidup sejahtera lahir dan batin dengan memiliki tempat tinggal/rumah yang layak dalam lingkungan hidup yang baik, sehat, aman, nyaman, terjangkau dan produktif. Namun demikian atas sejumlah kajian ditemukan adanya permasalahan teknis maupun non-teknis yang erat kaitannya dengan permasalahan pada penyelenggaraan sistem manajemen pemeliharaan rusun oleh badan pengelola rusun. Memahami bahwa sistem manajemen pemeliharan rusun bersifat kompleks yang ditandai oleh adanya sejumlah aspek dan faktor maka kajian dimaksudkan untuk mengidentifkasi faktorfaktor pada setiap aspek yang ada serta memetakan sejauh mana faktor-faktor tersebut dilaksanakan oleh pihak terkait. Hasil indentifikasi didapatkan 22 faktor penyelenggaraan sistem manajemen pemeliharaan yang dapat dikelompokkan atas lima aspek. Survei yang dilakukan pada delapan rusun yang dikelola oleh masing-masing PPPSRS di DKI Jakarta didapatkan tidak seluruh faktor dilaksanakan. Tiga PPPSRS melaksanakan tidak mencapai sepertiga faktor yang diidentifikasi. Sisanya, lima PPPSRS melaksanakan lebih dari dua pertiga faktor yang ada. Atas hasil survei dan analisis disimpulkan bahwa untuk memperkuat pelaksanaan faktof-faktor tersebut, disarankan untuk melaksanakan pelatihan bagi anggota PPPSRS dengan maksud agar terjadi peningkatan kemampuan badan pengelola rusun.
\end{abstract}

Kata Kunci: DKI Jakarta, rumah susun, sistem manajemen pemeliharaan

Abstract: Flats are concrete form of government policies in the provision of residence in urban area.
In their operation, flats are required to be managed and maintained. Such treatment are required in
order to achieve a goal which was defined in the Constitution of the Republic of Indonesia 1945 and
Act No. 4 of 1992 that every citizen has right to have prosperous life physically and mentally by
having habitable house in good environment, healthy, safe, comfortable, affordable, and productive.
However, according to some studies technical and non-technical problems were found. Technical
problems are connected to the building function. These problems cannot be separated from
administration problems of flat maintenance management system. Being aware that flat maintenance
management system is a complex system, this paper intends to identify the factors which include

${ }^{\mathbf{1}}$ Program Magister Teknik Sipil Konsentrasi Manajemen Proyek Konstruksi, Program
Pascasarjana Universitas Katolik Parahyangan

Korespondensi: andrevan@unpar.ac.id 
into different aspects as well as investigate how far those factors implemented. Based on identification, 22 factors of maintenance management system organization were generated and they were divided into five aspects. Survey which is done on eight flats that is managed by each PPPSRS in Special Capital Region of Jakarta finds that not all factors are done. Three PPPSRS do less than one third of those identified factors. The rest of them, five PPPSRS do more than two third of those factors. Based on survey and analysis found that capacity building enhancement is a must for PPPSRS in order to improve factor implementation level.

Keywords: flat, maintenance management system, Special Capital Region of Jakarta

\section{PENDAHULUAN}

Dalam Undang-undang Dasar (UUD) 1945 pasal 28h ayat (1) serta Undang-undang (UU) No.4 tahun 1992 pasal 5 dirumuskan cita-cita bahwa setiap orang/warga negara berhak hidup sejahtera lahir dan batin dengan memiliki tempat tinggal/rumah yang layak dalam lingkungan hidup yang baik, sehat, aman, nyaman, terjangkau dan produktif. Dalam tulisannya pada laman http://perumahan.pu.go.id, Permadi, D. (2017), menguraikan tentang adanya 11,4 juta keluarga di Indonesia belum memiliki rumah. Rumah yang adapun kurang lebih 3,4 juta unit tidak layak huni. Oleh karena itu pada tahun 2017, Kementerian PUPR berupaya dengan merencanakan pembangunan 128.549 unit, terdiri atas 13.466 unit rusun, 5.083 unit rumah khusus dan 110.000 unit rumah swadaya.

Pembangunan rusun adalah merupakan kebijakan pemerintah dalam menyediakan tempat tinggal di perkotaan sebagai akibat dari terbatas dan mahalnya lahan. Krisis tersediaan lahan sendiri adalah merupakan fenomena global sebagai akibat dari peningkatan pertumbuhan penduduk dan ekonomi yang terjadi hampir seluruh kota besar di dunia (AlKodmany,K. dan Ali, M.M., 2013). Kebijakan pemerintah dalam mendorong pembangunan rumah susun dirumuskan pada UU No 20 Tahun 2011 tentang Rumah Susun. Undangundang tersebut menyatakan bahwa negara bertanggung jawab melindungi segenap bangsa Indonesia dalam penyelenggaraan perumahan melalui rumah susun yang layak bagi kehidupan yang sehat, aman, harmonis, dan berkelanjutan di seluruh wilayah Indonesia.

Rusun adalah bangunan gedung hunian vertikal. Pada pasal 1 ayat 2, UU No 20 Tahun 2011, dalam penyelenggaraannya rusun wajib dikelola, dipelihara dan dirawat. Upaya pengelolaan, pemeliharaan dan perawatan ini menjadi penting agar paling tidak adanya anggapan responden pada penelitian yang dilakukan oleh Murbaintoro, T. dkk. (2009) bahwa rusun berpotensi dapat menimbulkan kekumuhan baru dapat ditepis. Untuk itu upaya pemeliharaan dan perawatan rusun sebagai sebuah bangunan gedung hunian vertikal menjadi mutlak dilakukan. Hal ini sejalan dengan rumusan pada Peraturan Menteri Pekerjaan Umum (Permen PU) No. 24/PRT/M/2008, tentang Pedoman Pemeliharaan dan Perawatan Bangunan Gedung. Menurut Permen PU No. 24/PRT/M/2008, bahwa pemeliharaan bangunan gedung adalah kegiatan menjaga keandalan bangunan gedung beserta prasarana dan sarananya agar bangunan gedung selalu laik fungsi. Disamping itu perawatan bangunan gedung adalah kegiatan memperbaiki dan/atau mengganti bagian bangunan gedung, komponen, bahan bangunan, dan/atau prasarana dan sarana agar bangunan gedung tetap laik fungsi.

Berdasarkan sejumlah kajian yang dilakukan oleh baik itu lembaga seperti Badan Perlindungan Konsumen Nasional (BPKN), Yayasan Lembaga Konsumen Indonesia (YLKI) ataupun beberapa akademisi didapati adanya sejumlah permasalahan terkait dengan penyelenggaraan rumah rusun ini. Permasalahan tersebut diantaranya berkenaan dengan permasalahan hukum (Pusat Litbang Permukiman dalam Suhaeni, 2009; Elmaliza, 2010), permasalahan badan pengelola (Kompas, 2011; Sudaryatmo, 2016), permasalahan teknis dan kualitas bangunan (BPKN, 2012; Labombang dan Rifai , 2012) termasuk pemeliharaan bangunan rusun paska konstruksi (Pusat Litbang Permukiman dalam Suhaeni, 2009). Selain 
itu, terkait permasalahan kelaikan fungsi gedung, kajian BPKN dan Labombang dan Rifai (2012) menemukan kondisi yang membahayakan keselamatan jiwa penghuni sebagai akibat dari adanya kebocoran pipa, kebocoran lantai kamar mandi, kualitas lift yang rendah, drainase yang tidak berfungsi dan genangan yang terjadi pada jalan lokal. Mencermati permasalahan kelaikan fungsi gedung berupa rusun ini ditengarai tidak dapat dilepaskan dari permasalahan pada badan pengelola rusun sebagai penyelenggara sistem manajemen pemeliharaan rusun termasuk sistem manajemen pemeliharaan itu sendiri.

Pada sisi lain, berdasarkan sejumlah kajian pada terkait manajemen pemeliharaan baik pada gedung ataupun prasarana umum ditemukan bahwa dalam manajemen pemeliharaan bukan hanya sekedar tindakan teknis, tetapi bersifat multidisiplin (Olanrewaju, 2010). Disiplin yang dimaksud adalah engineering, technological, commercial, economic dan social perspectives. Sementara Roy, dkk. (2003) menyatakan bahwa sistem manajemen pemeliharaan memerlukan perhatian pada paling tidak empat aspek: aspek organisasi, aspek keuangan, aspek teknis dan aspek administratif. Demikian pula Ervianto (2007) paling tidak menyatakan ada dua aspek, yaitu aspek biaya dan aspek organisasi. Dapat dipahami bahwa penggunaan istilah disiplin atau aspek merujuk maksud yang sama sebagai pernyataan pengelompokkan atau kategori faktor-faktor pemeliharaan yang perlu menjadi perhatian.

Menurut Olanrewaju, dkk. (2010), Ervianto (2007), Roy dkk. (2003), kurangnya pengelolaan secara terstruktur dan komprehensif pada aspek-aspek yang terkait akan mengakibatkan kinerja dari pemeliharaan gedung atau prasarana umum menurun. Pada gilirannya akan berdampak pada kinerja operasi atau fungsionalitas gedung atau prasarana umum tersebut. Dalam konteks permasalahan yang ditemukan pada rusun oleh BPKN, YLKI dan sejumlah akademisi memberikan indikasi bahwa ada kelemahan pada pengelolaan aspek-aspek yang dimaksudkan sebelumnya. Untuk itu pada penelitian ini akan dikaji faktorfaktor yang ada pada setiap aspek sebagai penentu keberhasilan penyelengaraan sistem manajemen pemeliharaan gedung hunian, khususnya rusun. Atas faktor-faktor tersebut akan diteliti sejauh mana pelaksanaannya oleh badan pengelola rusun untuk beberapa rusun di DKI Jakarta.

\section{METODE}

Berdasarkan atas uraian pada latar belakang, maka terdapat dua tujuan dalam penelitian ini. Pertama adalah identifikasi faktor-faktor manajemen pemeliharaan pada pada setiap aspek sebagai penentu keberhasilan penyelengaraan sistem manajemen pemeliharaan gedung hunian, khususnya rusun. Kedua mengetahui sejauh mana pemenuhan pelaksanaan atau penerapan fakto-faktor manajemen pemeliharaan oleh badan pengelola rusun untuk beberapa rusun di DKI Jakarta. Untuk dapat mencapai dua tujuan tersebut diagram alir pada Gambar 1. memberikan ilustrasi tahapan yang dilakukan pada penelitian ini. Penelitian ini bersifat deskriptif kualitatif, sehingga dalam upaya untuk dapatkan fakta-fakta atas variabel penelitian yang telah dirumuskan sebelumnya, dilakukan penyusunan dan penyebaran instrumen kuesioner. Proses verifikasi atas fakta yang diperoleh juga dilakukan dengan wawancara. Atas fakta-fakta dan informasi yang diperoleh dari sejumlah responden tersebut, proses penelitian dilanjutkan dengan pengolahan dan analisis data untuk kemudian dapat ditarik kesimpulan.

Merujuk pada Gambar 1, maka tujuan pertama tercapai pada proses kedua, sedangkan tujuan kedua tercapai pada proses keenam. Untuk dapat mencapai tujuan pertama maka sejumlah hasil penelitian termasuk peraturan yang ada akan ditelaah untuk mendapatkan faktor-faktor manajemen pemeliharaan penentu keberhasilan penyelengaraan sistem manajemen pemeliharaan rusun. Pada tujuan kedua, analisis penerapan faktor-faktor pelaksanaan penentu keberhasilan penyelengaraan sistem manajemen pemeliharaan gedung hunian dilakukan dengan menyusun kuesioner serta menyebarkannya pada 
sejumlah responden badan pengelola rusun. Badan pengelola rusun yang dimaksudkan pada penelitian ini adalah Perhimpunan Pemilik dan Penghuni Satuan Rumah Susun (PPPSRS). Keberadaan PPPSRS sebagai badan pengelola rusun adalah sesuai dengan amanat UU No 20 Tahun 2011 tentang Rumah Susun. Sementara rusun yang dipilih sebagai objek penelitian adalah rusun yang telah memiliki masa operasi di atas 15 tahun. Angka 15 tahun dipilih dengan kerangka pendekatan pemikiran bahwa keberadaan dan operasi PPPSRS dianggap telah memiliki sistem kerja yang stabil.

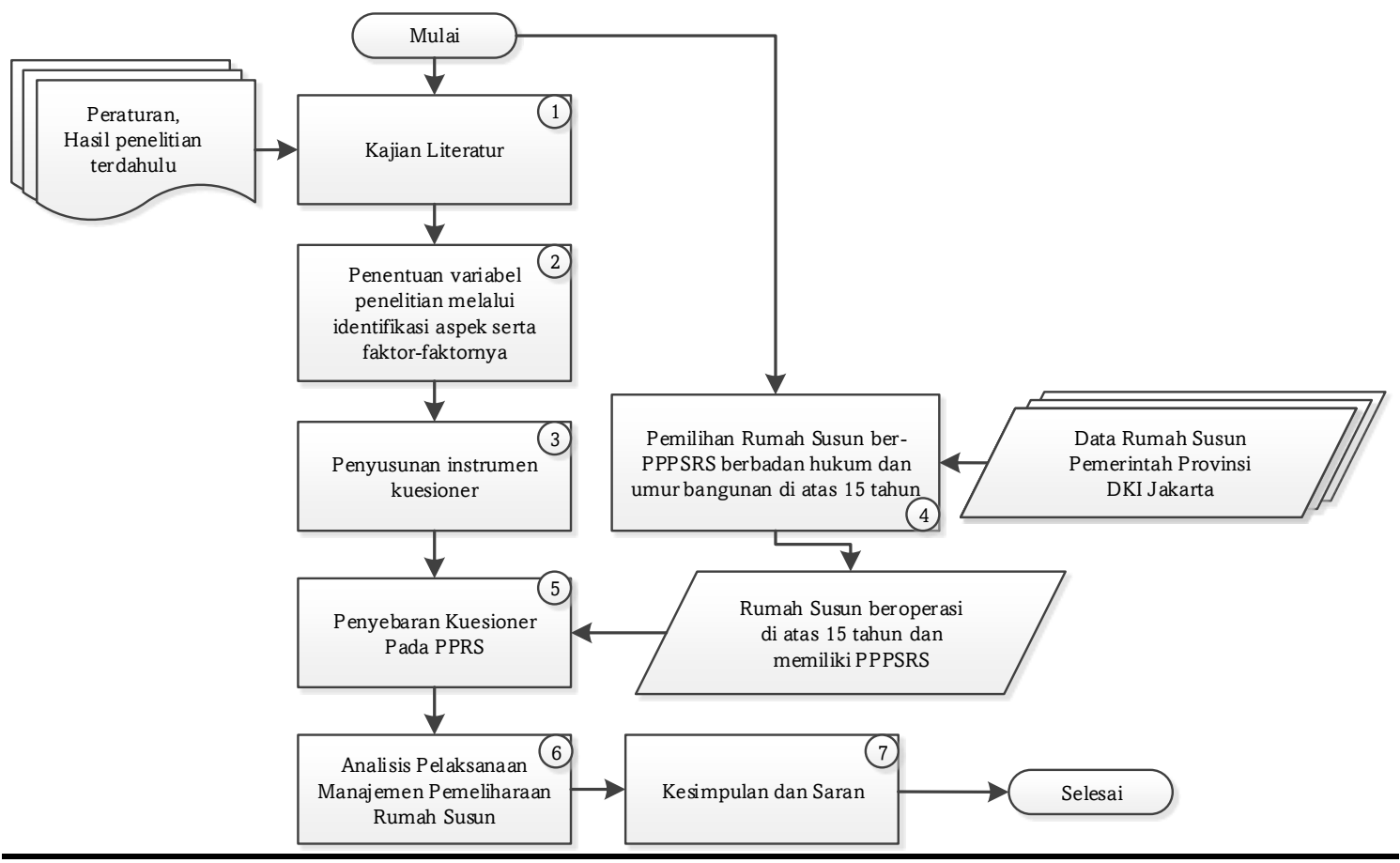

Gambar 1. Diagram Alir Penelitian

\section{Konsep dan Aspek-aspek Pemeliharaan Gedung}

Menurut British Standard (BS) 3811:1984 dalam Chanter dan Swallow (2007) pemeliharaan adalah sebuah kombinasi setiap tindakan yang dilakukan untuk mempertahankan kondisi sebuah item, atau mengembalikannya ke dalam kondisi yang dapat diterima. Sementara berdasarkan Permen PU No.24/PRT/M/2008 tentang Pedoman Pemeliharaan dan Perawatan Bangunan Gedung, memisahkan definisi antara pemeliharaan dan perawatan. Pemeliharaan bangunan gedung adalah kegiatan menjaga keandalan bangunan gedung beserta prasarana dan sarananya agar bangunan gedung selalu laik fungsi (preventive maintenance). Sementara perawatan bangunan gedung adalah kegiatan memperbaiki dan/atau mengganti bagian bangunan gedung, komponen, bahan bangunan, dan/atau prasarana dan sarana agar bangunan gedung tetap laik fungsi (corrective maintenance). Pemisahan istilah dipahami sebagai pemisahan antara preventive maintenance dan corrective maintenance. Berdasarkan telaah pada paling tidak enam referensi dari tahun 1997 sampai dengan 2007 tentang definisi pemeliharaan maka Olanrewaju dan Azis (2015) menyimpulkan bahwa pemeliharaan gedung adalah:

"the required processes and services taken to preserve, sustain, protect and care for a building's fabric, structure and engineering services after completion, repair, refurbishment or replacement to 
current standards to enable it to serve its intended functions throughout its entire life span without drastically up setting its basic features and use"

Chanter dan Swallow (2007) menyatakan bahwa dalam definisi pemeliharaan BS 3811:1984 terdapat dua komponen utama. Komponen pertama, tindakan pemeliharaan bukan sekedar aksi pemeliharaan, tetapi juga terkait dengan inisiasi pemeliharaan, pembiayaan serta masalah organisasi. Komponen kedua, terkait dengan kriteria kondisi yang dapat diterima. Hampir senada dengan komponen pertama Chanter dan Swallow (2007) ruang lingkup pengaturan Permen PU No. 24/PRT/M/2008 meliputi pengelolaan pemeliharaan dan perawatan, tata cara dan metode, sistem dan program, perlengkapan, peralatan dan standar kinerja pemeliharaan dan perawatan bangunan gedung, serta pembinaan. Dua referensi ini mengindikasikan kegiatan pemeliharaan memerlukan adanya aksi pengelolaan atau manajemen. Fakta ini juga dikemukakan oleh Ajiboye dan Adedokun (2010) yang menyatakan bahwa ada hubungan kuat antara pemeliharaan dan manajemen.

Selain itu merujuk kepada publikasi Building Departement of Hongkong tahun 2013 dalam Building Maintenance Guidebook menyatakan secara tersirat manajemen pemeliharaan bukan hanya tentang aspek keamanan dan kebersihan dasar bangunan, tetapi di dalamnya berkaitan dengan masalah koordinasi yang mencakup rencana dan pelaksanaan pemeliharaan untuk memastikan lingkungan hidup yang aman dan menyenangkan. Beberapa referensi tersebut secara tidak langsung menjelaskan bahwa kegiatan pemeliharaan haruslah dikelola dengan sistematis. Olanrewaju dan Aziz (2015) dan Queensland Department of Housing and Public Works (2012), menyatakan lebih tegas bahwa dalam kegiatan pemeliharaan tidak dapat lepas dari fungsi-fungsi manajemen berupa kegiatan planning, organizing, directing dan controlling.

Buildings Department, The Government of the Hongkong Special Administrative Region pada publikasinya “Building Maintenance Guidebook" pada tahun 2013, Sullivan, dkk. (2010), Olanrewaju (2010), Peraturan Pemerintah (PP) Republik Indonesia No. 4 Tahun 1988, tentang Rumah Susun, Permen PU No. 24/PRT/M/2008, CIBSE Maintenance Task Group (2008), Wordsworth (2000), kemudian juga hasil kajian Wulfram (2007) dan Roy, dkk. (2003), mengemukakan secara tersurat maupun tersirat bahwa terdapat sejumlah aspek yang harus dikelola dalam penyelenggaraan manajemen pemeliharan bangunan gedung. Berdasarkan inventarisasi atas sejumlah referensi tersebut, maka aspek-aspek yang sifatnya internal bagi pengelola ini meliputi aspek organisasi/kelembagaan, aspek keuangan, aspek teknis, aspek administratif serta aspek hukum. Gambar 1 menyajikan kelima aspek yang disintesis dari sumber-sumber yang disebutkan sebelumnya.

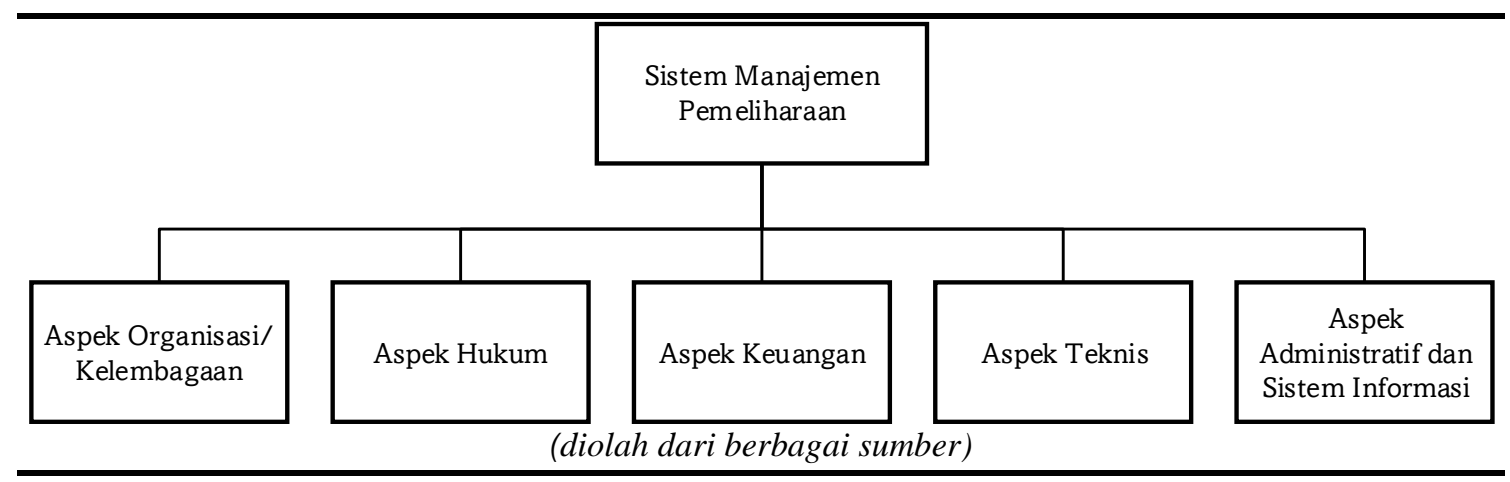

Gambar 2. Lima aspek dalam Manajemen Pemeliharaan Gedung

Sejumlah aspek ini dapat dipandang sebagai sejumlah sub-sistem. Seluruh sub-sistem ini harus berkolaborasi membentuk sebuah sistem manajemen pemeliharaan yang 
komprehensif dan terintegrasi (Roy, dkk., 2003, Olanrewaju, dkk., 2010). Olanrewaju, dkk. (2010) berargumen jika penyelengaraan sistem manajemen pemeliharaan tidak dilakukan secara komprehensif akan berakibat pada sulitnya penilaian kinerja pemeliharaan. Maintenance backlog akan semakin naik. Hal ini akan berdampak pada kinerja operasional (fungsi) gedung yang pada gilirannya mengganggu para pengguna gedung, hingga akhirnya dapat menurunkan produktivitas bahkan kualitas hidup penggunanya.

\section{Identifikasi Faktor-faktor Manajemen Pemeliharaan Rumah Susun}

Dalam penelitiannya sistem manajemen pemeliharaan jaringan distribusi air bersih PDM Kota Bandung, Roy, dkk (2003) melakukan telaah lebih dalam pada empat aspek. Adanya konsekuensi pengaturan sumber daya, metode kerja pemeliharaan, anggaran pemeliharaan, pengelolaan data dan lainnya mencerminkan bahwa pada masing-masing aspek memiliki turunan yang harus dikelola. Jika turunan tersebut disebut sebagai faktorfaktor, maka kelemahan pengelolaan pada satu faktor akan memiliki dampak pada kinerja penyelenggaraan manajemen pemeliharaan itu sendiri.

Terdapat sejumlah kajian dan referensi membahas mengenai faktor-faktor dalam penyelenggaraan pemeliharaan gedung. Sebagai contoh dalam Permen PU No. 24/PRT/M/2008 dalam aspek organisasi pemeliharaan terdapat pengaturan terhadap: faktor struktur organisasi, faktor tugas, tanggung jawab dan wewenang (deskripsi kerja), faktor komposisi sumber daya manusia, dan faktor pembekalan dan pelatihan. Melengkapi faktor yang disebutkan pada Permen PU No. 24/PRT/M/2008, pada Peraturan Daerah (PerDa) Propinsi DKI Jakarta No. 7 Tahun 2010 disebutkan bahwa pemeliharaan dan pengelolaan bangunan harus dilakukan oleh tenaga ahli pemeliharaan bangunan. Hal ini mengindikasikan perlunya pengelolaan untuk faktor kompetensi sumber daya manusia dalam sistem manajemen pemeliharaan gedung. Faktor pentingnya kompetensi sumber daya manusia juga disinggung oleh Zawawi dan Kamaruzzaman (2009) serta Chan, dkk. (2001). Lebih jauh Roy, dkk. (2003) menyatakan selain kompetensi (kualitas) sumber daya manusia juga perlu diperhatikan kuantitas sumber daya manusia. Faktor ini harus diperhatikan agar terjadi keseimbangan antara beban kerja pemeliharaan dan jumlah sumber daya manusianya.

Hasil kajian Roy, dkk. (2003), Ervianto (2007), Permen PU No. 24/PRT/M/2008, Olanrewaju, dkk. (2010), Labombang dan Rifai (2012), Isma, dkk. (2012) serta Waziri, dan Vanduhe (2013) menemukan sejumlah faktor terkait aspek keuangan. Faktor-faktor tersebut diantaranya faktor pembiayaan, faktor anggaran dan faktor pengawasan penggunaan anggaran yang harus dikelola.

Mengacu pada Gambar 2. masih terdapat sejumlah faktor yang terkait dengan tiga aspek lainnya yang disinggung oleh sejumlah referensi. Tabel 1 berikut menyajikan hasil indentifikasi faktor-faktor sistem manajemen pemeliharaan pada rusun yang dikelompokkan berdasarkan lima aspek seperti yang digambarkan pada Gambar 2.

Berdasarkan telaah atas tiga belas literatur diperoleh 22 faktor manajemen pemeliharaan rusun yang dapat dikelompokkan atas lima aspek. Empat faktor pada aspek organisasi, satu faktor pada aspek hukum, tiga faktor pada aspek keuangan, sembilan faktor pada aspek teknis dan sisanya lima faktor pada aspek administratif - sistem informasi. Hasil identifikasi 22 faktor ini selanjutnya diubah menjadi variabel penelitian yang dioperasionalkan menjadi sebuah instrumen penelitian dalam bentuk kuesioner.

\section{Data dan Analisa}

Berdasarkan data yang diperoleh dari situs Satu Data Indonesia pada bagian Daftar Rumah Susun Sederhana di DKI Jakarta, rusun di DKI Jakarta tersebar di lima wilayah yang 
berbeda. Atas data yang diperolah diketahui bahwa rentang masa operasi rusun termuda adalah 7 tahun dan yang tertua adalah 32 tahun. Pada lima wilayah tersebut terdapat total 48 lokasi rusun dengan jumlah mencapai 304 blok. Terdapat berbagai macam pengelola pada 48 lokasi tersebut seperti Perumnas, Dinas Perumahan, PD. Sarana Jaya, Yayasan Swasta, PPPSRS dan lainnya. Seperti dapat dilihat pada Tabel 2, hanya ada delapan buah pengelola dalam bentuk PPPSRS.

Tabel 1. Identifikasi Faktor-faktor Manajemen Pemeliharaan Rumah Susun

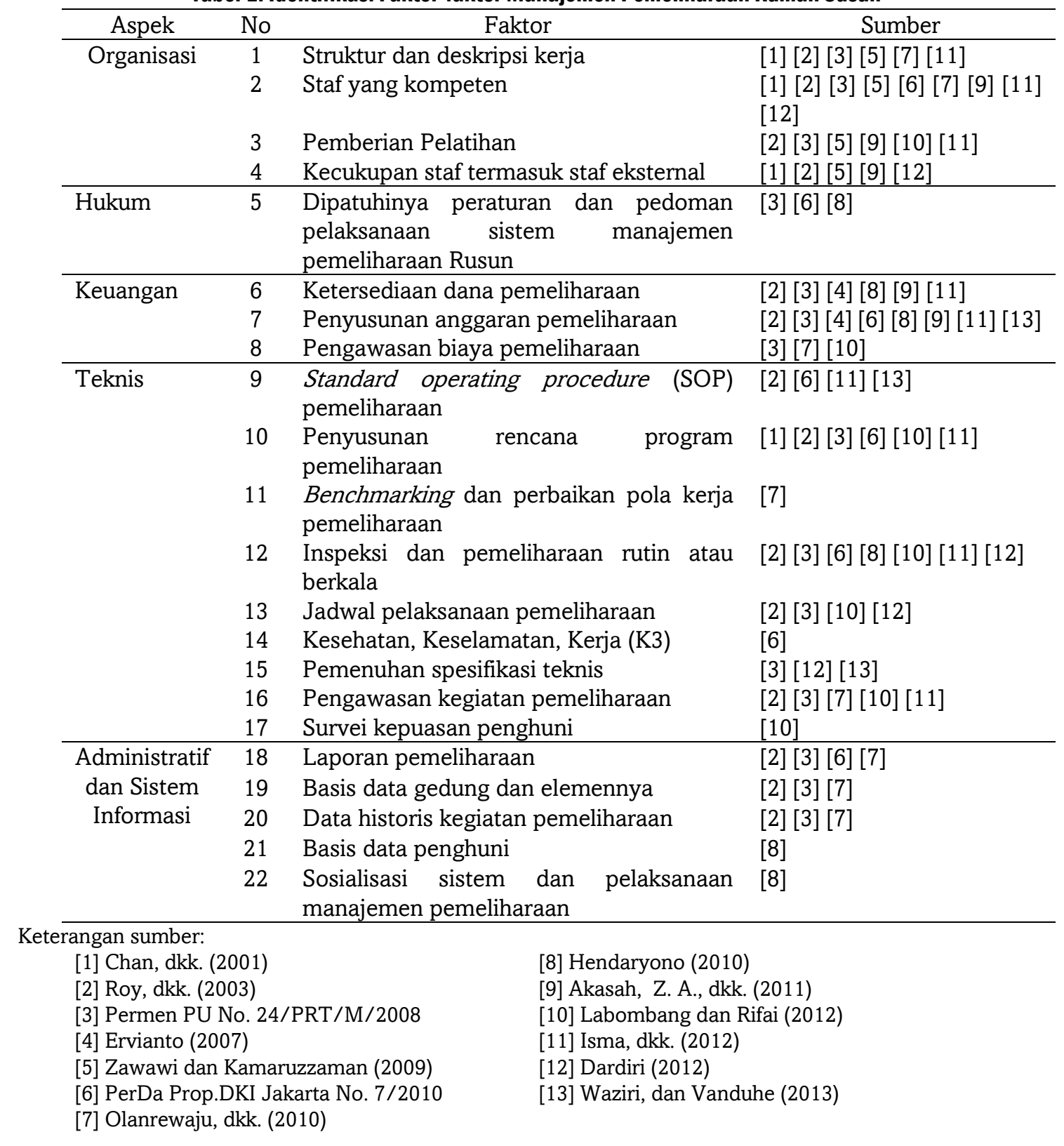


Tabel 2. Jumlah Rumah Susun di DKI Jakarta dan Dikelola PPPSRS

\begin{tabular}{lccc}
\hline \multirow{2}{*}{ Wilayah } & \multicolumn{2}{c}{ Jumlah } & Dikelola PPSRS \\
\cline { 2 - 3 } & Lokasi & Blok & \\
\hline Jakarta Pusat & 10 & 32 & 5 \\
Jakarta Utara & 11 & 107 & 0 \\
Jakarta Barat & 7 & 79 & 1 \\
Jakarta Selatan & 2 & 7 & 1 \\
Jakarta Timur & 18 & 79 & 1 \\
Jumlah & 48 & 304 & 8 \\
\hline
\end{tabular}

Sumber: Olahan dari Daftar Rusun Sederhana di DKI Jakarta

Untuk dapat mencapai tujuan kedua penelitian kedelapan lokasi rusun yang memiliki PPPSRS akan menjadi responden penelitian. Tabel 3 menyajikan data ke delapan lokasi rusun yang dikelola PPPSRS termasuk data lamanya beroperasi.

Tabel 3. Data Delapan Rusun DKI yang dikelola PPPSRS

\begin{tabular}{llrc}
\hline Wilayah & Nama Rumah Susun & Luas Lahan $\left(\mathrm{m}^{2}\right)$ & Masa Operasi RuSun (tahun) \\
\hline Jakarta Pusat & Tanah Tinggi II & 3.205 & 21 \\
& Jatibunder & 1.000 & 20 \\
& Bendungan Hilir II & 12.165 & 20 \\
& Karet Tengsin & 7.537 & 20 \\
& Petamburan & 22.466 & 16 \\
Jakarta Barat & Tambora III A & 7.400 & 24 \\
Jakarta Selatan & Tebet Barat I & 17.619 & 21 \\
Jakarta Timur & Kalimati (Bidara Cina) & 13.849 & 20 \\
\hline \multicolumn{3}{c}{ Sumber: Olahan dari Daftar Rumah Susun Sederhana di DKI Jakarta }
\end{tabular}

Responden penelitian adalah anggota badan pengelola rusun atau PPPSRS. Berdasarkan wawancara pada pihak PPPSRS, kepengurusan terdiri atas dua kelompok, pengurus inti dan wakil penghuni. Umumnya pengurus inti terdiri dari ketua, wakil, bagian humas dan beberapa tenaga teknisi, sementara wakil penghuni yang umumnya adalah Ketua atau Wakil Rukun Tetangga (RT) ataupun penghuni biasa. Pada tiap rusun dipilih empat anggota badan pengelola sebagai responden. Kuesioner yang disusun dibagikan kepada empat anggota tersebut. Sementara dalam proses pengisiannya dilakukan pendampingan langsung. Hal ini dilakukan untuk memastikan responden memahami maksud dari setiap faktor. Disamping itu juga dimaksudkan agar dapat dilakukan penggalian informasi lebih dalam terkait pelaksanaan faktor-faktor manajemen pemeliharaan oleh pihak PPPSRS.

Tabel 4. Penilaian Pelaksanaan Faktor- Faktor Sistem Manajemen Pemeliharaan Rusun

\begin{tabular}{|c|c|c|c|c|c|c|c|c|c|c|c|c|c|c|c|c|c|c|c|c|c|c|c|c|}
\hline \multirow{2}{*}{$\begin{array}{l}\text { Wilayah } \\
\text { Jakarta }\end{array}$} & \multirow{2}{*}{ Nama Rusun } & \multicolumn{22}{|c|}{ Faktor-faktor penyelenggaraan sistem manajemen pemeliharaan Rusun } & \multirow{2}{*}{$\begin{array}{l}\mathrm{Jm} \\
\mathrm{lh} .\end{array}$} \\
\hline & & 1 & 2 & 3 & 4 & 5 & 6 & 7 & 8 & 9 & 10 & 11 & 12 & 13 & 14 & 15 & 16 & 17 & 18 & 19 & 20 & 21 & 22 & \\
\hline \multirow{5}{*}{ Pusat } & Tanah Tinggi & 0 & 0 & 0 & 0 & 0 & 0 & 0 & 0 & 0 & 0 & 0 & 1 & 1 & 0 & 0 & 1 & 0 & 1 & 0 & 0 & 1 & 0 & 5 \\
\hline & Jati Bunder & 1 & 1 & 0 & 0 & 0 & 1 & 1 & 1 & 0 & 1 & 1 & 1 & 1 & 0 & 1 & 1 & 0 & 1 & 1 & 1 & 1 & 1 & 16 \\
\hline & Bendungan Hilir & 1 & 1 & 0 & 0 & 1 & 1 & 1 & 1 & 1 & 1 & 0 & 1 & 1 & 1 & 1 & 1 & 0 & 1 & 0 & 1 & 1 & 1 & 17 \\
\hline & Karet Tengsin & 1 & 1 & 0 & 1 & 0 & 1 & 1 & 1 & 1 & 1 & 0 & 1 & 1 & 0 & 1 & 1 & 0 & 1 & 1 & 1 & 1 & 1 & 17 \\
\hline & Petamburan & 1 & 1 & 0 & 0 & 0 & 1 & 1 & 1 & 1 & 1 & 1 & 1 & 1 & 1 & 0 & 1 & 0 & 1 & 1 & 1 & 1 & 1 & 17 \\
\hline Barat & Tambora IIIA & 0 & 0 & 0 & 0 & 0 & 1 & 1 & 1 & 0 & 0 & 0 & 0 & 1 & 0 & 0 & 1 & 0 & 0 & 0 & 0 & 1 & 1 & 7 \\
\hline Selatan & Tebet Barat I & 1 & 1 & 0 & 0 & 1 & 1 & 1 & 1 & 1 & 1 & 0 & 1 & 1 & 0 & 1 & 1 & 1 & 1 & 0 & 1 & 1 & 1 & 17 \\
\hline Timur & Kalimati (Bidara Cina) & 0 & 0 & 0 & 0 & 0 & 0 & 0 & 1 & 0 & 0 & 0 & 1 & 1 & 0 & 0 & 0 & 0 & 1 & 0 & 1 & 1 & 0 & 6 \\
\hline \multicolumn{2}{|c|}{ \% Pelaksanaan Keseluruhan } & 63 & 63 & 0 & 13 & 25 & 75 & 75 & 88 & 50 & 63 & 25 & 88 & 100 & 25 & 50 & 88 & 13 & 88 & 38 & 75 & 100 & 75 & \\
\hline
\end{tabular}

Sistem penilaian pelaksanaan faktor-faktor yang menggambarkan pemenuhan penyelenggaraan sistem manajemen pemeliharaan rusun dilakukan dengan pendekatan biner. Nilai 0 diberikan jika faktor tersebut tidak dilaksanakan dan nilai 1 diberikan jika faktor 
tersebut dilaksanakan. Tabel 4 menyajikan hasil penilaian pelaksanaan faktor-faktor penyelenggaraan sistem manajemen pemeliharaan rusun di delapan lokasi rusun di DKI Jakarta.

Gambar 3. memberikan ilustrasi persentase pelaksanaan faktor-faktor manajemen pemeliharaan rusun di antara 8 rusun di DKI Jakarta. Merujuk pada Gambar 3, maka tidak ada pihak PPPSRS yang melaksanakan seluruh 22 faktor secara lengkap. Tiga PPPSRS melaksanakan kurang dari sepertiga faktor yang teridentifikasi. Sisanya, lima PPPSRS, melaksanakan lebih dari dua pertiga faktor yang terindentifikasi.

Paling tidak ada dua faktor yang dilaksanakan oleh semua badan pengelola yaitu adanya dimilikinya basis data penghuni dan pembuatan jadwal pemeliharaan. Hal ini mudah dipahami karena sebagai PPPSRS harus mengetahui rincian warga yang menjadi tanggung jawabnya. Selain itu data ini umumnya, pada tahap awal terbentuknya PPPSRS, didapatkan dari pengembang ataupun Dinas Perumahan dan Gedung DKI. Dengan demikian sifatnya PPPSRS mendapatkan "hibah" data penghuni. Sementara dalam kaitannya dengan jadwal pemeliharaan, maka pihak PPPSRS berkepentingan dalam memberi informasi kepada penghuni serta mengawal proses kerja pemeliharaan beserta hasilnya.

Sementara satu-satunya faktor yang tidak pernah dilakukan adalah pelatihan. Berdasarkan wawancara mendalam yang dilakukan paling tidak terdapat dua temuan. Pertama badan pengelola merasa tidak perlu adanya pelatihan. Hal ini disebabkan oleh tenaga yang dimiliki saat ini telah memadai (sudah terampil). Temuan kedua terkait tidak adanya pelaksanaan pelatihan disebabkan oleh tidak pernah adanya program pelatihan yang ditawarkan oleh pihak yang berwenang, dalam hal ini Dinas Perumahan dan Gedung DKI.

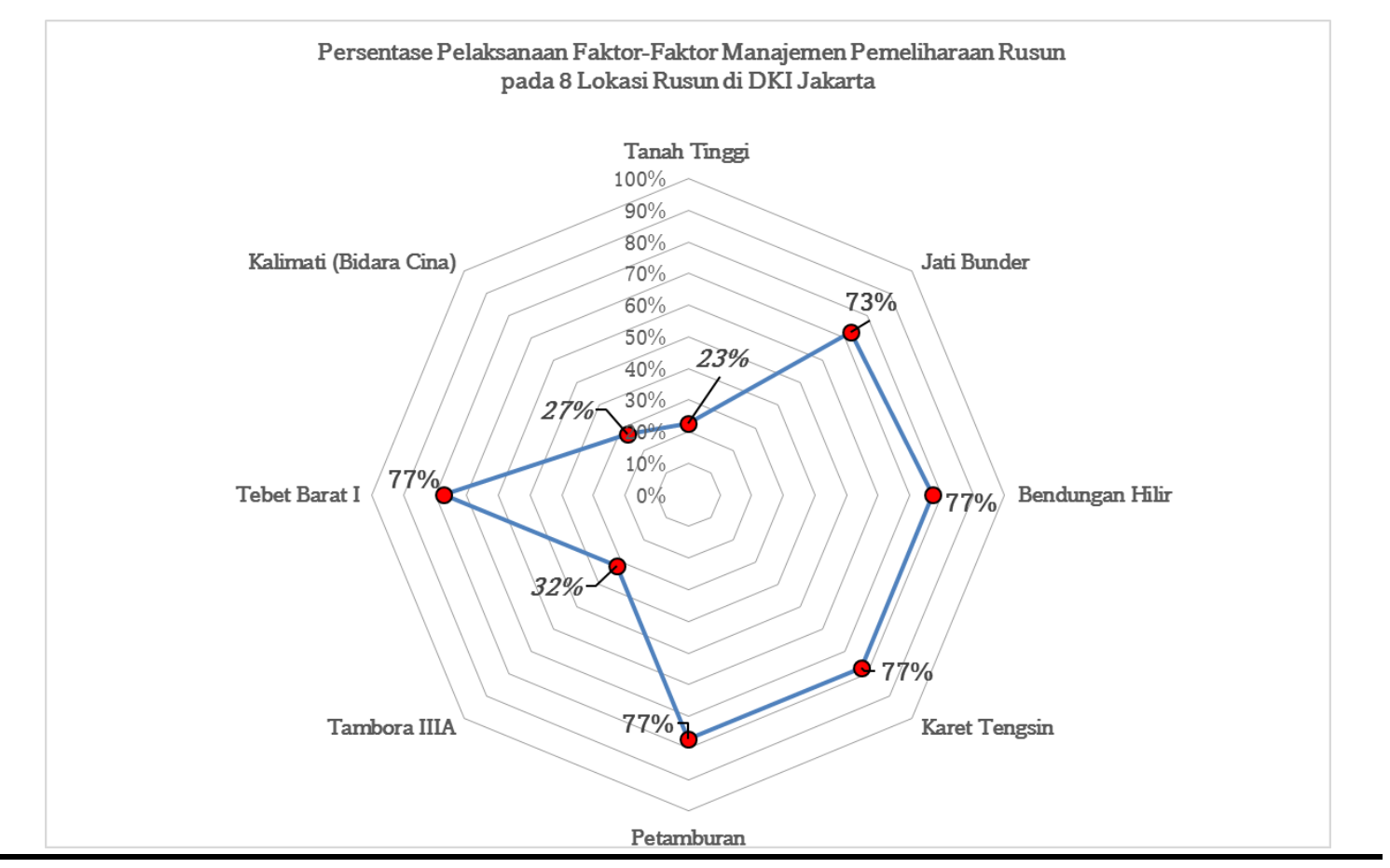

Gambar 3. Diagram Radar Persentase Pelaksanaan Faktor-Faktor Sistem Manajemen Pemeliharaan Rusun

Patut diduga badan pengelola menganggap bahwa bentuk pelatihan hanya terkait dengan pelatihan teknis tentang perbaikan elemen-elemen rusun. Untuk itu persepsi peserta pelatihan hanya untuk tenaga teknisi atau tukang. Padahal pelatihan seharusnya juga 
menyangkut bagaimana penyelenggaraan sistem manajemen pemeliharaan sebuah rusun secara menyeluruh meliputi seluruh aspek dan faktor turunannya. Jenis pelatihan yang bersifat menyeluruh ini bukan hanya untuk level teknisi atau tukang, tetapi diperuntukkan untuk level manajerial badan pengelola dalam rangka meningkatkan kapasitasnya. Hal lain, tidak adanya tawaran pelatihan dapat diakibatkan belum adanya program serta anggaran yang dialokasikan oleh dinas terkait.

Berdasarkan Tabel 1 jumlah faktor yang dapat diidentifikasi per aspeknya adalah: empat untuk aspek organisasi, satu untuk aspek hukum, tiga untuk aspek keuangan, sembilan untuk aspek teknis dan lima untuk aspek administrasi dan sistem informasi. Tabel 5 menyajikan informasi jumlah dan persentase faktor yang dilaksanakan per aspeknya. Sementara Gambar 4 memberikan ilustrasi persentase pelaksanaan faktor-faktor yang diakumulasikan pada setiap aspeknya.

Tabel 5. Agregat Faktor yang Dilaksanakan Per Aspek

\begin{tabular}{|c|c|c|c|c|c|c|c|c|c|c|c|}
\hline \multirow{3}{*}{$\begin{array}{r}\text { Wilayah } \\
\text { Jakarta }\end{array}$} & \multirow{3}{*}{ Nama Rusun } & \multicolumn{10}{|c|}{ Aspek } \\
\hline & & \multicolumn{2}{|c|}{ Organisasi } & \multicolumn{2}{|c|}{ Hukum } & \multicolumn{2}{|c|}{ Keuangan } & \multicolumn{2}{|c|}{ Teknis } & \multicolumn{2}{|c|}{ Adm.Sis.Info. } \\
\hline & & Dilaksn. & \% dilaksn. & Dilaksn. & $\%$ dilaksn. & Dilaksn. & $\%$ dilaksn. & Dilaksn. & $\%$ dilaksn. & Dilaksn. & \% dilaksn. \\
\hline \multirow{5}{*}{ Pusat } & Tanah Tinggi & 0 & $0 \%$ & 0 & $0 \%$ & 0 & $0 \%$ & 3 & $33 \%$ & 2 & $40 \%$ \\
\hline & Jati Bunder & 2 & $50 \%$ & 0 & $0 \%$ & 3 & $100 \%$ & 6 & $67 \%$ & 5 & $100 \%$ \\
\hline & Bendungan Hilir & 2 & $50 \%$ & 1 & $100 \%$ & 3 & $100 \%$ & 7 & $78 \%$ & 4 & $80 \%$ \\
\hline & Karet Tengsin & 3 & $75 \%$ & 0 & $0 \%$ & 3 & $100 \%$ & 6 & $67 \%$ & 5 & $100 \%$ \\
\hline & Petamburan & 2 & $50 \%$ & 0 & $0 \%$ & 3 & $100 \%$ & 7 & $78 \%$ & 5 & $100 \%$ \\
\hline Barat & Tambora IIIA & 0 & $0 \%$ & 0 & $0 \%$ & 3 & $100 \%$ & 2 & $22 \%$ & 2 & $40 \%$ \\
\hline Selatan & Tebet Barat I & 2 & $50 \%$ & 1 & $100 \%$ & 3 & $100 \%$ & 7 & $78 \%$ & 4 & $80 \%$ \\
\hline Timur & Kalimati (Bidara Cina) & 0 & $0 \%$ & 0 & $0 \%$ & 1 & $33 \%$ & 2 & $22 \%$ & 3 & $60 \%$ \\
\hline \multicolumn{2}{|c|}{ Rerata Pelaksanaan perAspek } & & $34 \%$ & & $25 \%$ & & $79 \%$ & & $56 \%$ & & $75 \%$ \\
\hline
\end{tabular}

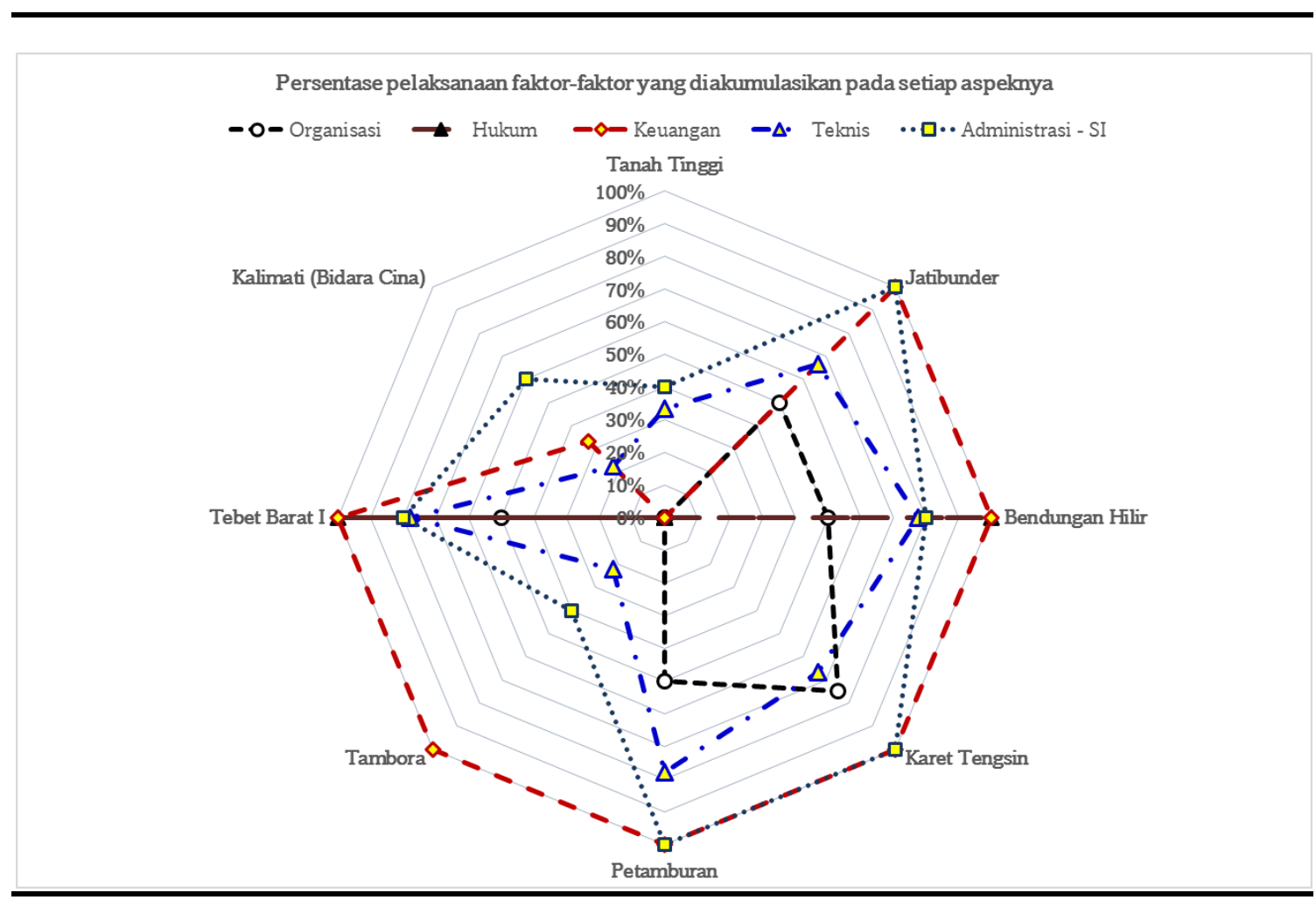

Gambar 4 . Diagram Radar Persentase Pelaksanaan Faktor-faktor per Aspek

Dapat dilihat pada Tabel 5 dan Gambar 4 bahwa pada umumnya pelaksanaan faktorfaktor pada aspek keuangan menjadi yang tertinggi pelaksanaannya. Pada umumnya 
PPPSRS memiliki dana pemeliharaan, membuat anggaran pemeliharaan dan mengawasi penggunaannya. Berdasarkan wawancara, enam dari delapan PPPRSRS membuat anggaran dalam periode tahunan, semesteran dan yang paling kecil dalam periode bulanan. Bervariasinya periode penganggaran ini ditengarai disebabkan oleh lancar tidaknya iuran dari para penghuni yang berakibat pada proses perencanaan pemeliharaan itu sendiri.

Namun demikian tidak untuk dua PPPSRS sisanya, yaitu Tanah Tinggi, dan Kalimati (Bidara Cina). Pada kedua lokasi rusun ini kedua PPPSRS tidak melakukan pengganggaran pemeliharaan. Berdasarkan telaah lebih dalam dengan wawancara, ditemukan dua permasalahan. Permasalahan tersebut ada pada sisi penghuni juga badan pengelola. Partisipasi penghuni kurang dalam hal kepedulian akan lingkungannya, sehingga berimbas kepada kurangnya iuran. Akibat kekurang pedulian penghuni ini berimbas pada sulitnya badan pengelola melakukan perencanaan pemeliharaan, termasuk perencanaan anggaran akibat tidak tersedianya dana pemeliharaan. Kondisi ini memverifikasi mengapa PPPSRS tidak dapat melaksanakan faktor sosialisasi sistem dan pelaksanaan manajemen pemeliharaan.

Sementara faktor pada aspek Hukum adalah yang terlemah pelaksanaannya. Faktor tersebut adalah dipatuhinya peraturan dan pedoman pelaksanaan sistem manajemen pemeliharaan rusun. Berdasarkan wawancara, ditemukan fakta bahwa sebagian besar (75\%) PPPSRS tidak mengetahui adanya pedoman pemeliharaan gedung. Temuan ini memverifikasi hasil analisis sebelumnya, bahwa pelatihan menjadi perlu diberikan kepada PPPSRS. Pelatihan bukan hanya terkait dengan teknis perbaikan elemen rusun, tetapi juga harus terkait dengan sistem manajemen pemeliharaan rusun secara menyeluruh. Untuk itu pelatihan sepatutnya diberikan secara komprehensif meliputi seluruh aspek beserta faktorfaktor terkait. Di samping itu, untuk mengantisipasi tidak dimilikinya dana untuk pelatihan oleh badan pengelola (PPPSRS), sudah sepatutnya pihak dinas terkait yang melakukan inisiasi diselenggarakannya program pelatihan.

\section{KESIMPULAN}

Berdasarkan telaah pada tiga belas literatur baik dalam bentuk hasil penelitian maupun peraturan dalam rentang tahun 2001 sampai dengan 2013 diperoleh 22 faktor manajemen pemeliharaan. Masing-masing faktor dapat dikelompokkan atas lima aspek yaitu aspek organisasi, aspek keuangan, aspek teknis dan aspek administrasi dan sistem informasi. Empat faktor masuk dalam aspek organisasi. Satu faktor masuk dalam aspek hukum. Tiga faktor masuk dalam aspek keuangan. Sembilan faktor masuk dalam aspek teknis dan sisanya lima faktor masuk dalam aspek administrasi dan sistem informasi.

Terdapat tiga PPPSRS yang tingkat pelaksanaan faktor manajemen pemeliharaannya rendah atau tidak mencapai sepertiga dari faktor yang berhasil diidentifikasi. Sementara sisanya, lima PPPSRS melaksanakan lebih dari dua pertiga faktor yang ada. Terdapat dua faktor yang dilaksanakan oleh seluruh PPPSRS yaitu pembuatan jadwal pemeliharaan dan pembuatan basis data penghuni. Sementara faktor yang tidak dilaksanakan seluruh PPPSRS adalah faktor pelatihan. Pada sisi lain jika merujuk pada perspektif pelaksanaan aspek maka aspek keuangan adalah yang tertinggi pelaksanaanya dan aspek hukum adalah yang terendah.

Berdasarkan hasil temuan atas tidak atau dilaksanakannya faktor-faktor maka pelatihan secara komprehensif bagi anggota PPPSRS adalah hal yang penting dan perlu untuk dilakukan. Pelatihan diperlukan agar PPPSRS memiliki staf manajerial yang lebih kompeten. Dengan demikian dapat diharapkan anggota PPPSRS dapat melaksanakan faktorfaktor sistem manajemen pemeliharaan dengan lebih baik. Dengan peningkatan kapasitas staf manajerial PPPSRS diharapkan mereka dapat mengembangkan cara-cara kreatif dalam melaksanakan tugasnya. 


\section{DAFTAR PUSTAKA}

---- $\quad$ Undang-Undang Dasar Negara Republik Indonesia. Tahun 1945;

---- Undang-Undang Republik Indonesia Nomor 4 Tahun 1992 tentang Perumahan dan Permukiman

---- $\quad$ Undang-Undang Republik Indonesia Nomor 20, Tahun 2011 tentang Rumah Susun;

---- Peraturan Pemerintah Republik Indonesia Nomor 4 Tahun 1988 tentang Rumah Susun

---- Peraturan Menteri Pekerjaan Umum No. 24/PRT/M/2008, tentang Pedoman Pemeliharaan dan Perawatan Bangunan Gedung;

---- $\quad$ Peraturan Daerah Propinsi DKI Jakarta No. 7 Tahun 2010, tentang Bangunan Gedung

Akasah, Z. A., Abdul, R. M. A., Zuraidi S. N. F. 2011. Maintenance management success factors for heritage building: a framework. WIT Transactions on The Built Environment, Vol 118, pp. 653-658

Al-Kodmany, K., Ali, M.M., Zhang, T. 2013. Importing Urban Giants: Re-Imaging Shanghai and Dubai with Skyscrapers. International Journal of Architectural Research, Volume 7.2, pp. 22-42.

Building Maintenance Guidebook. [Homepage of Buildings Department, The Government of the Hongkong Special Administrative [Online]. Avion] Available at: http://www.bd.gov.hk/english/documents/code/bmg/bmg.htm. Diakses pada tanggal 16 Desember 2016

CIBSE Maintenance Task Group. 2010. Maintenance engineering and management - A guide for designers, maintainers, building owners and operators, and facilities managers. The Chartered Institution of Building Services Engineers London

Chan, K.T., Lee, R.H.K., Burnett, J. 2001. Maintenance performance: a case study of hospitality engineering systems. Facilities, Vol. 19 Issue: 13/14, pp.494-504

Chanter, B. dan Swallow, P. 2007. Building Maintenance Management. 2nd Edition, Blackwell Publishing

Daftar Rumah Susun Sederhana di DKI Jakarta. [Homepage of Satu Data Indonesia] [Online] Available at: https://data.go.id/dataset/daftar-rumah-susun-sederhana-di-dki-jakarta. Diakses pada Desember 2016

Dardiri, A. 2012. Analisis Pola, Jenis, dan Penyebab Kerusakan Bangunan Gedung Sekolah Dasar. Teknologi dan Kejuruan, Vol. 35, No. 1, pp. 71-80

Ervianto, W.I. 2007. Studi Pemeliharaan Bangunan Gedung (Studi Kasus Gedung Kampus). Jurnal Teknik Sipil. Program Studi Teknik Sipil Universitas Atma Jaya Yogyakarta, Vol. 7, No. 3: 212-22.

G. P. Sullivan, G.P., Pugh, R., Melendez, A.P., Hunt, W.D. 2010. Operations \& Maintenance -Best Practices - A Guide to Achieving Operational Eficiency. Federal Energy Management Program, U.S. Department of Energy.

Hendaryono, S.M. 2010. Evaluasi Pengelolaan Rusun Pekunden Dan Bandarharjo Semarang. Tesis. Program Pascasarjana Magister Teknik Pembangunan Wilayah Dan Kota Universitas Diponegoro Semarang

Isma, F., Afifuddin, M., Aulia, B. 2012. Kajian Pengorganisasian Pemeliharaan Bangunan Gedung Sekretariat Daerah Kabupaten Aceh Tengah. Jurnal Teknik Sipil Pascasarjana Universitas Syiah Kuala, Vo., No. 1, pp. $112-120$

Labombang, M. dan Rifai, A. 2012. Manajemen Pemeliharaan Rumah Susun Sederhana Sewa (Rusunawa) di Kecamatan Palu Barat. Jurnal Teknik Sipil, Infrastruktur, Vol 2, No 1.

Murbaintoro, T., Ma'arif, M.S., Sutjahyo, S.H., Saleh, I. 2009. Model Pengembangan Hunian Vertikal Menuju Pembangunan Perumahan Berkelanjutan. Jurnal Permukiman, Volume 4.2, pp. 72-87

Olanrewaju, A.L. 2010. Quantitative Analysis of Criteria in University Building Maintenance in Malaysia. Australasian Journal of Construction Economics and Building, 10 (3) 51-61

Olanrewaju, A.L., Khamidi, M.F., Idrus, A. 2010. Building Maintenance Management in a Malaysian University Campuses: A Case Study. Australasian Journal of Construction Economics and Building, 10 (1/2) 76-89

Olanrewaju, A. L., Abdul-Aziz, A.R. 2015. Building Maintenance Processes and Practices - The Case of a Fast Developing Country. Springer Science+Business Media Singapore.

Permadi, D, 2017. Reorientasi Kebijakan Penyediaan Perumahan, Belajar dari pengalaman negara Asia Pasifik dalam pertemuan ke 6 'Asia Pacific Ministerial Conference on Housing and Urban Development' (APMCHUD). [Homepage of Direktorat Jenderal Penyediaan Rumah Kementerian Pekerjaan Umum dan Perumahan Rakyat] [Online]. Available at: http://perumahan.pu.go.id/ditpnp/berita/show/104. Diakses pada tanggal 7 Januari 2017

Penghuni Keluhkan Masalah Rumah Susun. [Homepage of Kompas.Com] [Online] Available at: http://properti.kompas.com/read/2011/04/17/12211539/Penghuni.Keluhkan.Masalah.Rumah.Susun. Diakses pada Desember 2016 
Queensland Department of Housing and Public Works. 2012. Maintenance Management Framework - Building Maintenance Policy, Standards and Strategy Development. The State of Queensland, Australia.

Roy, A.F.V, Triweko, R.W., Joewono, T.B.. 2002. Kajian Sistem Manajemen Pemeliharaan Jaringan Distribusi Air Bersih di PDAM Kota Bandung. Jurnal Teknik Sipil, Vol. 4 No. 1, ISSN:1411-5360

Sudaryatmo, 2016. Mencermati Masalah Rumah Susun. [Homepage of Yayasan Lembaga Konsumen Indonesia] [Online]. Available at: http://ylki.or.id/2016/05/mencermati-masalah-rumah-susun/. Diakses pada tanggal 16 Desember 2016

Suhaeni, H. 2009. Pembangunan Rumah Susun dalam Mendukung Aktivitas Ekonomi Perkotaan (Studi Kasus Kota Bandung). Jurnal Permukiman, Volume 4.2, pp. 102-109

T.K. Ajiboye \& G. Adedokun. 2010. Maintenance Engineering as a Basic Tool for Maximum Production. Pacific Journal of Science and Technology. 11(2):416-421.

Tim Badan Perlindungan Konsumen Nasional (BPKN). 2012. Perlindungan Konsumen Rumah Susun di Indonesia. [Homepage of Badan Perlindungan Konsumen Nasional] [Online]. Available at: http://bpkn.go.id/uploads/document/768d71cc23a26d3c03b8cbbfc223d2ef41862a31.pdf. Diakses pada tanggal 16 Desember 2016

Waziri, B.S., Vanduhe, B.A. 2013. Evaluation of Factors Affecting Residential Building Maintenance in Nigeria: Users' Perspective. Civil and Environmental Research, Vol.3, No.8, pp. 19-24

Wordsworth, P. 2000. Lee's Building Maintenance Management. 4th Edition. Wiley

Zawawi, E.M.A., Kamaruzzaman, S. N. 2009. Personnel Characteristics of Maintenance Practice: A Case of HighRise Office Buildings in Malaysia. Journal of Sustainable Development, Vol. 2, No. 1, pp. 111-11 